\title{
Review of Development of Live Vaccines against Leishmaniasis
}

\author{
Mohammad Hossein Feiz Haddad ${ }^{1,2}$ Jalal Lomei ${ }^{3} \quad$ Azar Shokri $^{4}$ Habib Habibpour ${ }^{1,2}$ Hossein Rezvan ${ }^{5}$ \\ Alireza Nourian ${ }^{5}$ Mohammad Reza Mahmoudi ${ }^{6}$ \\ ${ }^{1}$ Cellular and Molecular Research Center, Ahvaz Jundishapur \\ University of Medical Sciences, Ahvaz, Iran \\ 2 Department of Parasitology, Faculty of Medicine, Ahvaz Jundishapur \\ University of Medical Sciences, Ahvaz, Iran \\ ${ }^{3}$ Division of Integrative Physiology, Department of Medical Cell \\ Biology, Uppsala University, Uppsala, Sweden \\ ${ }^{4}$ Vector-borne Disease Research Center, North Khorasan University of \\ Medical Sciences, Bojnurd, Iran \\ ${ }^{5}$ Department of Pathobiology, Faculty of Veterinary Science, Bu-Ali \\ Sina University, Hamedan, Iran \\ ${ }^{6}$ Cellular and Molecular Research Center, School of Medicine, Guilan \\ University of Medical Sciences, Rasht, Iran \\ Address for correspondence Habib Habibpour, PhD, Department of \\ Parasitology, Faculty of Medicine, Ahvaz Jundishapur University of \\ Medical Sciences, Ahvaz, Iran (e-mail: h.habibpour59@gmail.com). \\ J Child Sci 2021;11:e178-e184.
}

\begin{abstract}
Keywords

- Leishmania

- leishmaniasis

- live-attenuated

- vaccine

Leishmaniasis is a serious public health problem in both tropical and temperate regions, caused by protozoan parasites of the genus Leishmania. Cutaneous leishmaniasis is the most common form of leishmaniasis worldwide. After recovery from the initial infection in most of the patients, a long-lasting natural immunity will be established. In individuals with HIV infection or in immune deficient patients, the more dangerous forms can occur. Despite many attempts, there is no efficient vaccine for leishmaniasis. The main concern for live-attenuated vaccines is the possibility of returning to the virulent form. Therefore, the safety is an important point in designing a successful vaccine. Nonvirulent parasites as vaccine candidates are achievable through gamma-irradiation, long-term culture, random mutations induced by chemical agents, and temperature-sensitive mutations. The type of change(s) in such parasites is not known well and drawbacks such as reversion to virulent forms was soon realized. Leishmania tarentolae with capacity of adaptation to mammalian system has a potential to be used as nonpathogenic vector in vaccine programs. Due to its nonpathogenic intrinsic property, it does not have the ability to replace with the pathogen form. Moreover, the main problems are associated with the production of live vaccines, including lyophilization, storage, standards, and quality control that must be considered. In this review, we focused on the importance of different approaches concerning the development of a live vaccine against leishmaniasis.
\end{abstract}

received

August 29, 2020

accepted after revision

May 14, 2021
DOI https://doi.org/

10.1055/s-0041-1731336.

ISSN 2474-5871. (c) 2021. The Author(s).

This is an open access article published by Thieme under the terms of the Creative Commons Attribution License, permitting unrestricted use, distribution, and reproduction so long as the original work is properly cited. (https://creativecommons.org/licenses/by/4.0/)

Georg Thieme Verlag KG, Rüdigerstraße 14, 70469 Stuttgart, Germany 


\section{Introduction}

Leishmaniasis, caused by an intracellular protozoan parasites of the genus Leishmania, is prevalent in subtropical and tropical regions all around the world. ${ }^{1-3}$ The disease is considered as neglected tropical diseases with the incidence of 1.5 million new cases annually ${ }^{4,5}$ which leads to a considerable mortality and morbidity. ${ }^{6}$ There are three main forms of the disease, namely, cutaneous leishmaniasis (CL), visceral leishmaniasis (VL), and mucocutaneous leishmaniasis (MCL). ${ }^{7} \mathrm{VL}$, also known as kala-azar, is caused by Leishmania donovani (anthroponotic form) and L. infantum (zoonotic form). VL is the most important and severe form of leishmaniasis with 500,000 new cases annually. In this form of the disease, the parasites invade in internal organs such as liver and spleen. VL can lead to death in untreated cases and there is no effective vaccine for it. ${ }^{8}$ MCL is mainly caused by $L$. braziliensis complex in mucosal tissues of nose and mouth and can result in massive tissue damage and permanent disfiguration. ${ }^{9} \mathrm{CL}$ is self-healing disease ${ }^{10}$ caused mostly by the L. tropica and L. major in the Central Asia and Middle East ${ }^{11}$ and $L$. braziliensis and $L$. mexicana complexes in the Americas. ${ }^{12} \mathrm{CL}$ is the most common form of leishmaniasis in the world, and $90 \%$ of all CL cases occur only in seven countries: Syria, Iran, Saudi Arabia, Algeria, Peru, Brazil, and Afghanistan. ${ }^{1} \mathrm{CL}$ can lead to skin deformities, and in immune compromised patients giving rise to the diffuse cutaneous leishmaniasis. ${ }^{13}$ The host immune response has a crucial role in leishmaniasis, both in efficacy of treatment and the clinical patterns of the disease. ${ }^{14}$ Success in development of vaccine depends on selecting an appropriate vaccine candidate and the immune biology of pathogen/host interactions. ${ }^{15}$ Cell-mediated immunity particularly CD4 T cells are critical in leishmaniasis and protection against the disease. ${ }^{16}$ The host defense mainly relies on response of Th1 cells which were activated through interleukin (IL)-12. Antigen presenting cells (APCs) and T cells, as they produce IL-12 and interferon gamma (IFN- $\gamma$ ), are crucial for limiting the numbers of leishmania parasites. ${ }^{17}$ In contrast, Th2 cells produce cytokines, mainly IL-4, IL-5, and IL-13 and anti-inflammatory cytokines that have suppressive effect on host immunity which leads to parasite survival during leishmaniasis. ${ }^{17,18}$ These effects are exclusively studied in CL and murine models. ${ }^{7,19}$ Generation of proper immunologic memory is the main challenge in designing a vaccine that can cause effective immunity. Different studies revealed that long-lasting immunity against leishmaniasis needs to involve the function of both regulatory $\mathrm{T}$ cells (Tregs) and Th1-mediated immune response. ${ }^{20,21}$ Currently, treatment of any form of leishmaniasis is remarkably dependent on pentavalent antimonials as first-line and amphotericin B as second-line drugs. ${ }^{22}$ This treatment is usually adequate but long duration of treatment, high costs, and side effects are still challenging. Reversion to virulence form has been reported in host with weak immune system, especially in HIV infected individuals. ${ }^{23}$ Furthermore, strains which are resistant to available drugs created the need for an effective vaccine. ${ }^{24}$ Currently, there is no impermissible vaccine
Table 1 Development status of current vaccine candidates

\begin{tabular}{|l|l|l|l|l|}
\hline $\begin{array}{l}\text { Candidate } \\
\text { name/identifier }\end{array}$ & Preclinical & $\begin{array}{l}\text { Phase } \\
\text { I }\end{array}$ & $\begin{array}{l}\text { Phase } \\
\text { II }\end{array}$ & Reference \\
\hline LEISH-F2 & & & $\mathrm{X}$ & 11,25 \\
\hline LEISH-F3 & & $\mathrm{X}$ & & 11,26 \\
\hline $\begin{array}{l}\text { Various Lutzomyia and } \\
\text { fly antigens }\end{array}$ & $\mathrm{X}$ & & & 11,27 \\
\hline $\begin{array}{l}\text { Various second- } \\
\text { generation protein- } \\
\text { based vaccines }\end{array}$ & $\mathrm{X}$ & & & 11,27 \\
\hline $\begin{array}{l}\text { Various third- } \\
\text { generation DNA- } \\
\text { based and } \\
\text { heterologous prime- } \\
\text { boost vaccines }\end{array}$ & $\mathrm{X}$ & & & 11,27 \\
\hline
\end{tabular}

against human leishmaniasis, even several vaccines have developed to clinical trials, most are still in early research phases and need more develop ( - Table 1). ${ }^{25-27}$ From 2004, four vaccines have been licensed against canine leishmaniosis, two in Brazil (Leishmune, license was withdrawn in 2014, and Leish-Tec) and two in Europe (CaniLeish and LetiFend). ${ }^{28}$ Efforts for finding an effective vaccine against leishmaniasis is continuing worldwide. ${ }^{9,29}$ Finally, development of an effective vaccine is one of the most cost-effective ways to eliminate and/or control CL and VL. This review aims to discuss the importance of different approaches concerning the development of a live-attenuated vaccine against leishmaniasis.

\section{Live Active Vaccines}

Leishmanization (LZ) was the first effort in using live parasite for human immunization, which was used in some countries for immunization against CL. There is a constant concern about revision to virulent type. This method was used in last century in several countries particularly in the Middle East, but it countered severe barriers such as local lesions in 2 to $3 \%$ of cases. The program was stopped due to some problems such as spreading the HIV infection, increasing the use of immunosuppressive drugs, permanent skin lesions, dissemination of lesions, ethical reasons, and problems in quality control of inoculant and long-lasting parasite persistence. Uzbekistan is one of the endemic countries, which LZ is licensed and its efficacy in human trials was proven. Efforts for improving the safety of this practice is continuing as this program can lead to an efficient vaccine against CL. It is declared that under controlled condition, it is achievable to elicit quick immune responses using the killed parasites and adjuvants. $^{30}$

\section{Live-Attenuated Vaccine}

Several methods such as long-term in vitro cultures, ${ }^{31}$ attenuation with temperature, ${ }^{32}$ chemical mutagenesis, ${ }^{33,34}$ 
culture under drug pressure, ${ }^{35}$ and $\gamma$-attenuation have been used to develop an attenuated Leishmania strains for many years. Recently, live-attenuated mutants through the gene alteration have revealed ability to induce proper immune responses in experimental hosts (-Table 2 ). This helps researchers to identify genes which are necessary for Leishmania parasite's survival and/or for their virulence. ${ }^{33,49-54}$

In summary, it is believed that live-attenuated parasites can be considered suitable vaccine candidate as they present antigens to the APCs and activate them to induce immunity through mimicking natural infection and lead to the highest rate of $\mathrm{CD} 4+\mathrm{T}$ cells polarization. ${ }^{55}$ Also, it evaluates the memory of the immune system due to delivery of whole antigens instead of its subunits, and finally, they cause antigen constancy through long time subclinical infection. Therefore, memory cells and subsequently antigen-specific responses will be produced and react to reinfection. ${ }^{56} \mathrm{~A}$ significant protection by attenuated parasites in murine models have been approved, but there is forever reversion capability that makes them inefficient for using them in

Table 2 Defined and undefined genetic alteration live-attenuated vaccines against leishmaniasis

\begin{tabular}{|c|c|c|c|c|}
\hline Species & Attenuation process & Model & Outcome of immunization & References \\
\hline L. tropica, L. major & Long-term in vitro culture & $\begin{array}{l}\mathrm{BALB} / \mathrm{C} \text { and } \\
\mathrm{C} 57 \mathrm{BL} / 6\end{array}$ & $\begin{array}{l}\text { Persistent low-grade cutaneous disease, } \\
\text { BALB/c: partially protection C57BL/6: } \\
\text { completely resistant }\end{array}$ & 31 \\
\hline L. major & Long-term in vitro culture & $\mathrm{BALB} / \mathrm{C}$ & Protection & 36 \\
\hline L. chagasi & Long-term in vitro culture & $\mathrm{BALB} / \mathrm{C}$ & No protection & 37 \\
\hline L. amazonensis & Long-term in vitro culture & $\mathrm{C} 57 \mathrm{BL} / 6$ & $\begin{array}{l}\text { Decrease parasite load, increased IFN- } \gamma \text {, smaller } \\
\text { lesions }\end{array}$ & 38 \\
\hline L. braziliensis & Temperature sensitivity & $\mathrm{BALB} / \mathrm{C}$ & Protection & 32 \\
\hline L. major & Radio attenuated & CBA & $\begin{array}{l}\text { Resistance to subsequent infection with } L \text {. } \\
\text { mexicana }\end{array}$ & 39 \\
\hline L. major & Gamma irradiation & $\mathrm{BALB} / \mathrm{C}$ and $\mathrm{CBA}$ & $\begin{array}{l}\text { Protection against heterologous and homologs } \\
\text { challenge }\end{array}$ & 33 \\
\hline L. infantum & In vitro under gentamicin pressure & Dog & $\begin{array}{l}\text { In the endemic area against canine visceral } \\
\text { leishmaniosis gentamicin-attenuated } L \text {. } \\
\text { infantum induced a strong and significant } \\
\text { protective effect }\end{array}$ & $40-42$ \\
\hline L. infantum & $\begin{array}{l}\text { KHARON1 (KH1) null mutants } \\
(\Delta \text { Likh1) }\end{array}$ & $\begin{array}{l}\text { BALB/C } \\
\text { Mice }\end{array}$ & $\begin{array}{l}\Delta \text { Likh1-immunized mice presented reduced } \\
\text { parasite burden upon challenging with virulent } \\
\text { L. infantum, when compared with naïve mice. An } \\
\text { effect associated with increased IL-17 } \\
\text { production and Li SLA-specific IgG serum levels }\end{array}$ & 43 \\
\hline L. infantum & $\begin{array}{l}\text { HSP70-II genes null mutant } \\
\text { (Li } \Delta \text { HSP70-II) }\end{array}$ & $\begin{array}{l}\mathrm{BALB} / \mathrm{C} \text { and } \\
\mathrm{C} 57 \mathrm{BL} / 6\end{array}$ & $\begin{array}{l}\text { Li } \Delta \text { HSP70-II attenuated line activates } \\
\text { mammalian immune system for inducing } \\
\text { moderate proinflammatory responses }\end{array}$ & 44 \\
\hline L. donovani & LdCen $\left(^{-1-}\right)$ centrin deleted & $\begin{array}{l}\text { Mice and } \\
\text { hamster }\end{array}$ & $\begin{array}{l}\text { LdCen }^{-1-} \text { live-attenuated vaccine induced a } \\
\text { strong antibody production, a selectively CD } 4+ \\
\text { and CD } 8+T \text { cell activation in addition to } \\
\text { prominent type } 1 \text { immune response that } \\
\text { contributed to a remarkable reduction in bone } \\
\text { marrow parasite load, even } 24 \text { months post- } L \text {. } \\
\text { infantum infection }\end{array}$ & 45 \\
\hline L. donovani & $\begin{array}{l}\text { Arabino-1, 4-lactone oxidase }(\Delta \mathrm{ALO}) \\
\text { null mutants }\end{array}$ & $\begin{array}{l}\text { BALB } / \mathrm{c} \\
\text { Mice }\end{array}$ & $\begin{array}{l}\text { Live-attenuated } \Delta \mathrm{ALO} \text { parasites are induce } \\
\text { protective immunity, safe, and can provide } \\
\text { sustained protection against } L \text {. donovani }\end{array}$ & 46 \\
\hline L. donovani & $\begin{array}{l}\left.\text { p27 gene-deleted (Ldp27 } 7^{-1-}\right) \text {, } \\
\text { Ldp27episomal add-back } \\
\text { (Ldp27-l-AB), Centrin } 1 \text { gene deleted } \\
\left.\text { (LdCen }{ }^{-1-}\right) \text {, and LdCen episomal } \\
\left.\text { add-back (LdCen }{ }^{-1-} \mathrm{AB}\right) \text { lines of } L \text {. } \\
\text { donovani }\end{array}$ & BALB/c mice & $\begin{array}{l}\text { Attenuated parasite-infected mice induced } \\
\text { higher IL-2 and IFN-y but significantly less IL-10 } \\
\text { production by ovalbumin-specific CD } 4+\mathrm{T} \text { cells, } \\
\text { resulting in the proliferation of Th1 cells }\end{array}$ & 47 \\
\hline L. donovani & $\begin{array}{l}\text { Centrin } 1 \text { and p } 27 \text { genes deleted live- } \\
\text { attenuated Leishmania parasites } \\
\left(L d C e n 1^{-1-} \text { and } L d p 27^{-1-}\right)\end{array}$ & $\begin{array}{l}\text { Human } \\
\text { macrophages }\end{array}$ & $\begin{array}{l}\text { LdCen } 1^{-I-} \text { and } L d p 27^{-I-} \text { strongly stimulated } \\
\text { production of proinflammatory cytokines } \\
\text { including, IL-12, IFN- } \gamma \text {, TNF- } \alpha \text {, IL-2, IL-6, and IL-17 } \\
\text { in the PBMCs }\end{array}$ & 48 \\
\hline
\end{tabular}

Abbreviations: IFN-y, interferon gamma; IgG, immunoglobulin G; IL, interleukin; TNF- $\alpha$, tumor necrosis factor $\alpha$. 
human vaccination programs. There is a great risk about consequent reactivation in HIV/Leishmania coinfected individuals along with increasing the asymptomatic cases. Additionally, attenuation may lead to poor immune response as the strains are not able to induce subclinical infection or they are not able to express necessary antigenic epitopes. Despite of satisfactory experimental results, the important safety points are needed for attention before using genetically attenuated parasitic vaccines. For achieving an effective memory response against Leishmania parasites, persistence of antigen by producing subclinical infections is worthwhile. Reactivation of Leishmania is shown in immunocompromised patients. This proves the importance of careful investigation of live-attenuated parasites which can cause subclinical infection. ${ }^{30}$

Based on the used attenuation procedure, live-attenuated parasites are divided in two groups: defined and undefined genetically modified ( - Table 2 ). ${ }^{57}$ In defined attenuation, by specific mutagenesis, the parasites lost the ability of encoding one or more essential virulence genes. Lazer irradiation or chemical mutagenesis or long-term in vitro culture can produce undefined attenuated parasites. In clinical trial performed in Iran with live vaccine, the researchers used stabilates which were made from stationary phase of parasites. They performed two trials in adults and followed them till healing the leishmanial lesions. ${ }^{15,58}$ There is a great challenge in using of live-attenuated Leishmania in the regions with high risk of HIV infection. Nowadays, the approved live-attenuated vaccines for clinical trials are made from $L$. major ${ }^{59}$ and that means the vaccine will be prepared soon and will be able to help protect masses against the other coexistence species in endemic areas. ${ }^{6}$

\section{Genetically Live-Attenuated Vaccines}

Genetically modified vaccines have been developed in recent years and are powerful tools for creating immunity. ${ }^{59}$ For achieving a protective vaccine, modifying some of Leishmania genes through deleting virulent or necessary genes seems to be successful. ${ }^{21}$ The transfection technology through modifying one or more genes in Leishmania parasite leads to a great affect. The DNA fragments could be transferred through physical methods such as electroporation to the parasite's nuclei. ${ }^{60}$ Antibiotic-resistant genes in a linear structure need to be combined with the genome through homologous recombination for removing a gene. Antibioticresistant genes in a linear form should be constructed and need to integrated by homolog recombining for removing a gene. This leads to transferring the sequence of DNA in genome of Leishmania parasite. ${ }^{60}$ To achieve an absolute knockout, there should be another construct to produce antibiotic-resistant gene by Leishmania parasite to set the alleles of the second gene. This manipulation leads to parasites new phenotype and features which hereditary transfer to the next generation. The main concern in gene targeting is the new gene location control as it is important that it should not interfere with genes normal function. Although the genome of Leishmania parasite is easily manipulated, the site of entered gene is important and should be confirmed by molecular genetics assays. Another important issue after gene transfer is the phenotype alterations and need to be studied more. In this regard, one of the famous experiments was performed by Titus et al who decided to vaccinate mice against virulent $L$. major parasite ${ }^{49}$ with dihydrofolate reductase-thymidylate synthase null mutant of the parasite, which they achieved through gene targeting. Unfortunately, it did not show persistent protection affect in susceptible mouse strains and in Rhesus monkeys ${ }^{61}$ but revealed the resistant phenotype of $L$. major parasite. ${ }^{49}$ Another attempt on mice and hamster, using mutants of manipulated $L$. Mexicana which lacked cysteine proteinase genes, showed promising results such as low parasite burden, smaller lesions, and delay in disease onset in animals were observed. ${ }^{52,62}$ These findings show that the protective immune response is achievable through genetic attenuation of live Leishmania parasite. In a study performed by Uzonna et al, they found that very susceptible mice were protected after vaccination with phosphoglycan (PG)-deficient L. major without considerable Th1 response. ${ }^{54}$ Experiments with BT1 null mutant of $L$. donovani in infecting mice in comparison to wild type were promising and the susceptible individuals were able to attain protective immunity against the parasite. $^{53}$ Other researchers proved the efficacy of live genetically attenuated Leishmania vaccines in inducing immunity as Silvestre et al demonstrated the production of IFNV/ IL-10 in SIR2-deficient L. infantum that seems to be protective. ${ }^{63}$ Other researchers tried to attain an effective vaccine with elimination of all PGs through deleting the lipophosphoglycan $(L P G)$ gene in $L$. major. This leads to creating a nonpathogen parasite, which obtained life ability at low level for more than 2 years in mice. Thus, immunization with $\operatorname{lpg} 2^{-}$parasites in very susceptible BALB/c mice induced protection against virulent $L$. major parasites. ${ }^{12}$ In another research performed by Kedzierski et al, vaccination with a virulent $L$. major with absence of phosphomannomutase in susceptible BALB/c mice induced a protective response. They declared that increase in Th cells and their role in lymph nodes during the infection and low levels of IL-13 and IL-10 are the main reason of protection against Leishmania parasites. ${ }^{64}$ In a 2009 study, it was revealed that by using of centrin gene (LdCen $1^{-l-}$ ) disrupted $L$. donovani parasites were able to protect susceptible BALB/c mice and immune-deficient mice and hamsters against infection with L. braziliensis. ${ }^{65}$ Fiuza et al showed that vaccination of dogs with LdCen $^{-l-}$ vaccine leads to Type 1 polarization and Type 2 inhibition along with production of antibody. ${ }^{62}$ It is shown by Dey et al that knockout of protein $27\left(\mathrm{Ldp}^{-1-}\right)$ in amastigotes of $L$. donovani can induce protection against other Leishmania species. ${ }^{47}$ Mutant of L. infantum which lacks both HSP70-II (DHSP70-II) alleles can protect BALB/c mice of infection with $L$. major, resulting in production of NO and type 1 immune responses with immunoglobulin $G$ subclass analyses as reported by Carrion et al. ${ }^{66} \mathrm{New}$ generation of live-attenuated vaccine from $L$. major strain $\left(\mathrm{LmCen}^{-1-}\right.$ ) for LZ has been explained by Zhang et al as they suggested effective protection against leishmaniasis 
without causing lesion. It seems the gene-free vaccine can be considered for human clinical trials in phase I. ${ }^{7}$ Some limitations including concern about probability of reversion to virulent form and using them in immune-deficient people and manufacturing problems make the use of these vaccine more difficult.

\section{Nonpathogenic Leishmania (Leishmania tarentolae)}

In a study conducted by Breton et al, the use of nonpathogenic Leishmania strain (L. tarentolae) as a vector for designing a vaccine for VL is suggested. ${ }^{67}$ The strain is harmless for human and in vitro evaluations revealed that the parasites are able to infect both human and murine phagocytic cells specially dendrite cells (DCs). Also, the parasites are able to promote DC maturation through monitoring their surface activation markers such as MHC-II, CD40, and CD83. ${ }^{67,68}$ The results obtained from experiments of $L$. tarentolae are comparable with the results of $L$. major infection in recruiting immune cells and producing inflammatory cytokines. Analysis of genome sequence has shown the similarity between pathogenic species including $L$. major, $L$. braziliensis, and $L$. infantum and $19 \%$ similarity between the shared genes in all species.

This suggests that some of these genes are related to the capacity of pathogenicity in this strain which makes it harmless to human. For instance, the presence of high copy number of amastin family in pathogenic species of Leishmania and presence of just two copies of L. tarentolae ${ }^{69}$ and this is the reason of $L$. tarentolae's inability for application in mammalian macrophages. A protective immune response against $L$. donovani in susceptible BALB/c mice has been induced by experimental intraperitoneal administration of $L$. tarentolae that leads to a conclusion that this was caused through presentation of enhanced antigen and effective response of Th1 cells. ${ }^{67}$ By considering the ability of gene manipulation and producing transgenic $L$. tarentolae which can be immune dominant antigens of Leishmania parasite, it would be considered as an effective vector in antileishmanial vaccines. The plan is using this strain of Leishmania as a special delivering and expressing leishmanial antigens system in host. Also, the A2 protein which is expressed by $L$. donovani complex and promotes visceralization of parasite is not present in L. tarentolae. Recent studies have demonstrated that the absence of virulence genes including $L P G 3, C P B$, GP63, and amastin is not related to the lack of pathogenicity in L. tarentolae. ${ }^{70}$ In a study, administration of A2-recombinant $L$. tarentolae vaccine was induced protection against $L$. infantum challenge in BALB/c mice and the protection was associated with production of high levels of IFN- $\gamma$ before and after challenge. ${ }^{71}$ As $L$. tarentolae is able to induce T-cellsmediated protection, it could be considered as a safe vector for live vaccines against Leishmania parasites and possibly other intracellular pathogens. Also, infection with L. tarentolae can elicit maturation of DC which are responsible for parasite phagosytose. ${ }^{72}$ Salehi et al designed and evaluated a live vaccine by using recombinant E7 protein which was expressed by $L$. tarentolae for protection of mice against human papillomavirus-associated tumors. Interestingly, the vaccine showed the best protection against TC-1-induced tumors $^{73}$. Comparative studies on $L$. tarentolae can be helpful for understanding the pathogenicity of Leishmania and its relationships with the host.

\section{Conclusion}

Despite the efforts of achieving an effective vaccine against leishmaniasis, there is still a long way to meet the vaccine development goals. Easy adaptation of Leishmania tarentolae and its safety to mammalian cells is promising to use it as a vector in live vaccines. However, it is important to take in considerations the major problems associated with production of live vaccines, including lyophilization, storage, standards, and quality control.

Note

The results described in this article were part of $\mathrm{PhD}$ student thesis of H.H.

\section{Funding}

This study was financially supported by Ahvaz Jundishapur University of Medical Sciences (grant no. CMRC-9820).

Conflict of Interest

None declared.

\section{References}

1 Torres-Guerrero E, Quintanilla-Cedillo MR, Ruiz-Esmenjaud J, Arenas R. Leishmaniasis: a review. F1000 Res 2017;6:750-750

2 Feiz Haddad MH, Ghasemi E, Maraghi S, Tavala M. Identification of Leishmania species isolated from human cutaneous leishmaniasis in Mehran, Western Iran using nested PCR. Iran J Parasitol 2016; 11(01):65-72

3 Hamoon NavardS, Rezvan H, Feiz Haddad MH, et al. Therapeutic effects of mesenchymal stem cells on cutaneous leishmaniasis lesions caused by Leishmania major. J Glob Antimicrob Resist 2020;23:243-250

4 Hotez PJ, Alvarado M, Basáñez M-G, et al. The global burden of disease study 2010: interpretation and implications for the neglected tropical diseases. PLoS Negl Trop Dis 2014;8(07): e2865

5 Vos T, Barber RM, Bell B, et al; Global Burden of Disease Study 2013 Collaborators. Global, regional, and national incidence, prevalence, and years lived with disability for 301 acute and chronic diseases and injuries in 188 countries, 1990-2013: a systematic analysis for the Global Burden of Disease Study 2013. Lancet 2015;386(9995):743-800

6 Zabala-Peñafiel A, Todd D, Daneshvar H, Burchmore R. The potential of live attenuated vaccines against cutaneous leishmaniasis. Exp Parasitol 2020;210:107849

7 Zhang WW, Karmakar S, Gannavaram S, et al. A second generation leishmanization vaccine with a markerless attenuated Leishmania major strain using CRISPR gene editing. Nat Commun 2020;11 (01):3461

8 Khatoon N, Pandey RK, Prajapati VK. Exploring Leishmania secretory proteins to design $\mathrm{B}$ and $\mathrm{T}$ cell multi-epitope subunit vaccine using immunoinformatics approach. Sci Rep 2017;7(01):8285

9 Mohammed ASA, Tian W, Zhang Y, Peng P, Wang F, Li T. Leishmania lipophosphoglycan components: a potent target for synthetic 
neoglycoproteins as a vaccine candidate for leishmaniasis. Carbohydr Polym 2020;237:116120

10 Bennis I, De Brouwere V, Belrhiti Z, Sahibi H, Boelaert M. Psychosocial burden of localised cutaneous leishmaniasis: a scoping review. BMC Public Health 2018;18(01):358

11 Gillespie PM, Beaumier CM, Strych U, Hayward T, Hotez PJ, Bottazzi ME. Status of vaccine research and development of vaccines for leishmaniasis. Vaccine 2016;34(26):2992-2995

12 de Vasquez AM, Saenz RE, Petersen JL, Christensen HA, Johnson CM. Leishmania mexicana complex: human infections in the Republic of Panama. Am J Trop Med Hyg 1990;43(06):619-622

13 Desjeux P. Leishmaniasis: current situation and new perspectives. Comp Immunol Microbiol Infect Dis 2004;27(05):305-318

14 Khalili G, Dobakhti F, Mahmoudzadeh-Niknam H, Khaze V, Partovi F. Immunotherapy with imiquimod increases the efficacy of glucantime therapy of Leishmania major infection. Iran J Immunol 2011;8(01):45-51

15 Srivastava S, Shankar P, Mishra J, Singh S. Possibilities and challenges for developing a successful vaccine for leishmaniasis. Parasit Vectors 2016;9(01):277

16 Bogdan C. Mechanisms and consequences of persistence of intracellular pathogens: leishmaniasis as an example. Cell Microbiol 2008;10(06):1221-1234

17 Maspi N, Abdoli A, Ghaffarifar F. Pro- and anti-inflammatory cytokines in cutaneous leishmaniasis: a review. Pathog Glob Health 2016;110(06):247-260

18 Hurdayal R, Brombacher F. The role of IL-4 and IL-13 in cutaneous leishmaniasis. Immunol Lett 2014;161(02):179-183

19 Kaye P, Scott P. Leishmaniasis: complexity at the host-pathogen interface. Nat Rev Microbiol 2011;9(08):604-615

20 Belkaid Y, Piccirillo CA, Mendez S, Shevach EM, Sacks DL. $\mathrm{CD} 4+\mathrm{CD} 25+$ regulatory $\mathrm{T}$ cells control Leishmania major persistence and immunity. Nature 2002;420(6915):502-507

21 Mendez S, Reckling SK, Piccirillo CA, Sacks D, Belkaid Y. Role for $\mathrm{CD} 4(+) \mathrm{CD} 25(+)$ regulatory $\mathrm{T}$ cells in reactivation of persistent leishmaniasis and control of concomitant immunity. J Exp Med 2004;200(02):201-210

22 Tiuman TS, Santos AO, Ueda-Nakamura T, Filho BP, Nakamura CV. Recent advances in leishmaniasis treatment. Int J Infect Dis 2011; 15(08):e525-e532

23 Bentwich Z. Concurrent infections that rise the HIV viral load. J HIV Ther 2003;8(03):72-75

24 Croft SL, Sundar S, Fairlamb AH. Drug resistance in leishmaniasis. Clin Microbiol Rev 2006;19(01):111-126

25 Duthie MS, Raman VS, Piazza FM, Reed SG. The development and clinical evaluation of second-generation leishmaniasis vaccines. Vaccine 2012;30(02):134-141

26 Nagill R, Kaur S. Vaccine candidates for leishmaniasis: a review. Int Immunopharmacol 2011;11(10):1464-1488

27 Rezvan H, Moafi M. An overview on Leishmania vaccines: a narrative review article. Vet Res Forum 2015;6(01):1-7

28 Velez R, Gállego M. Commercially approved vaccines for canine leishmaniosis: a review of available data on their safety and efficacy. Trop Med Int Health 2020;25(05):540-557

29 Bezerra IPS, Costa-Souza BLS, Carneiro G, Ferreira LAM, de Matos Guedes HL, Rossi-Bergmann B. Nanoencapsulated retinoic acid as a safe tolerogenic adjuvant for intranasal vaccination against cutaneous leishmaniasis. Vaccine 2019;37(28):3660-3667

30 Saljoughian N, Taheri T, Rafati S. Live vaccination tactics: possible approaches for controlling visceral leishmaniasis. Front Immunol 2014;5:134

31 Mitchell GF, Handman E, Spithill TW. Vaccination against cutaneous leishmaniasis in mice using nonpathogenic cloned promastigotes of Leishmania major and importance of route of injection. Aust J Exp Biol Med Sci 1984;62(Pt 2):145-153

32 Gorczynski RM. Immunization of susceptible BALB/c mice against Leishmania braziliensis. II. Use of temperature-sensitive avirulent clones of parasite for vaccination purposes. Cell Immunol 1985;94 (01):11-20

33 Rivier D, Shah R, Bovay P, Mauel J. Vaccine development against cutaneous leishmaniasis. Subcutaneous administration of radioattenuated parasites protects CBA mice against virulent Leishmania major challenge. Parasite Immunol 1993;15(02):75-84

34 Kimsey PB, Theodos CM, Mitchen TK, Turco SJ, Titus RG. An avirulent lipophosphoglycan-deficient Leishmania major clone induces $\mathrm{CD} 4+\mathrm{T}$ cells which protect susceptible BALB/c mice against infection with virulent $L$. major. Infect Immun 1993;61 (12):5205-5213

35 Daneshvar H, Coombs GH, Hagan P, Phillips RS. Leishmania mexicana and Leishmania major: attenuation of wild-type parasites and vaccination with the attenuated lines. J Infect Dis 2003; 187(10):1662-1668

36 Segovia M, Artero JM, Mellado E, Chance ML. Effects of long-term in vitro cultivation on the virulence of cloned lines of Leishmania major promastigotes. Ann Trop Med Parasitol 1992;86(04): 347-354

37 Streit JA, Recker TJ, Filho FG, Beverley SM, Wilson ME. Protective immunity against the protozoan Leishmania chagasi is induced by subclinical cutaneous infection with virulent but not avirulent organisms. J Immunol 2001;166(03):1921-1929

38 Gualdieri L, Rinaldi L, Petrullo L, et al. Intestinal parasites in immigrants in the city of Naples (southern Italy). Acta Trop 2011; 117(03):196-201

39 Alexander J. A radioattenuated Leishmania major vaccine markedly increases the resistance of CBA mice to subsequent infection with Leishmania mexicana. Trans R Soc Trop Med Hyg 1982;76 (05):646-649

40 Chettri JK, Deshmukh S, Holten-Andersen L, Jafaar RM, Dalsgaard I, Buchmann K. Comparative evaluation of administration methods for a vaccine protecting rainbow trout against Yersinia ruckeri O1 biotype 2 infections. Vet Immunol Immunopathol 2013;154 (1-2):42-47

41 Daneshvar H, Molaei MM, Kamiabi H, Burchmore R, Hagan P, Stephen Phillips R. Gentamicin-attenuated Leishmania infantum: cellular immunity production and protection of dogs against experimental canine leishmaniasis. Parasite Immunol 2010;32 (11-12):722-730

42 Daneshvar H, Sedghy F, Dabiri S, et al. Alteration in mononuclear cell subpopulations in dogs immunized with gentamicin-attenuated Leishmania infantum. Parasitology 2012;139(13): 1689-1696

43 Santi AMM, Lanza JS, Tunes LG, et al. Growth arrested liveattenuated Leishmania infantum KHARON1 null mutants display cytokinesis defect and protective immunity in mice. Sci Rep 2018; 8(01):11627

44 Solana JC, Ramírez L, Corvo L, et al. Vaccination with a Leishmania infantum HSP70-II null mutant confers long-term protective immunity against Leishmania major infection in two mice models. PLoS Negl Trop Dis 2017;11(05):e0005644

45 Fiuza JA, Gannavaram S, Santiago HdaC, et al. Vaccination using live attenuated Leishmania donovani centrin deleted parasites induces protection in dogs against Leishmania infantum. Vaccine 2015;33(02):280-288

46 Anand S, Madhubala R. Genetically engineered ascorbic aciddeficient live mutants of Leishmania donovani induce long lasting protective immunity against visceral leishmaniasis. Sci Rep 2015; 5:10706

47 Dey R, Dagur PK, Selvapandiyan A, Mccoy JP, Salotra P, Duncan R, et al. Live attenuated Leishmania donovani p27 gene knockout parasites are nonpathogenic and elicit long-term protective immunity in BALB/c mice. J Immunol 2013;190:2138-2149. Doi: 10.4049/jimmunol.1202801a

48 Avishek K, Kaushal H, Gannavaram S, et al. Gene deleted live attenuated Leishmania vaccine candidates against visceral 
leishmaniasis elicit pro-inflammatory cytokines response in human PBMCs. Sci Rep 2016;6:33059

49 Titus RG, Gueiros-Filho FJ, de Freitas LA, Beverley SM. Development of a safe live Leishmania vaccine line by gene replacement. Proc Natl Acad Sci U S A 1995;92(22):10267-10271

50 Dumas C, Ouellette M, Tovar J, et al. Disruption of the trypanothione reductase gene of Leishmania decreases its ability to survive oxidative stress in macrophages. EMBO J 1997;16(10):2590-2598

51 Hübel A, Krobitsch S, Hörauf A, Clos J. Leishmania major Hsp100 is required chiefly in the mammalian stage of the parasite. Mol Cell Biol 1997;17(10):5987-5995

52 Alexander J, Coombs GH, Mottram JC. Leishmania mexicana cysteine proteinase-deficient mutants have attenuated virulence for mice and potentiate a Th1 response. J Immunol 1998;161(12):6794-6801

53 Papadopoulou B, Roy G, Breton M, et al. Reduced infectivity of a Leishmania donovani biopterin transporter genetic mutant and its use as an attenuated strain for vaccination. Infect Immun 2002;70 (01):62-68

54 Uzonna JE, Späth GF, Beverley SM, Scott P. Vaccination with phosphoglycan-deficient Leishmania major protects highly susceptible mice from virulent challenge without inducing a strong Th1 response. J Immunol 2004;172(06):3793-3797

55 Spörri R, Reis e Sousa C. Inflammatory mediators are insufficient for full dendritic cell activation and promote expansion of CD4+ T cell populations lacking helper function. Nat Immunol 2005;6(02): $163-170$

56 Foulds KE, Wu CY, Seder RA. Th1 memory: implications for vaccine development. Immunol Rev 2006;211(01):58-66

57 Silvestre R, Cordeiro-da-Silva A, Ouaissi A. Live attenuated Leishmania vaccines: a potential strategic alternative. Arch Immunol Ther Exp (Warsz) 2008;56(02):123-126

58 Khamesipour A, Rafati S, Davoudi N, Maboudi F, Modabber F. Leishmaniasis vaccine candidates for development: a global overview. Indian J Med Res 2006;123(03):423-438

59 Alvar J, Croft SL, Kaye P, Khamesipour A, Sundar S, Reed SG. Case study for a vaccine against leishmaniasis. Vaccine 2013;31 (Suppl 2):B244-B249

60 Papadopoulou B, Dumas C. Parameters controlling the rate of gene targeting frequency in the protozoan parasite Leishmania. Nucleic Acids Res 1997;25(21):4278-4286

61 Amaral VF, Teva A, Oliveira-Neto MP, et al. Study of the safety, immunogenicity and efficacy of attenuated and killed Leishmania (Leishmania) major vaccines in a rhesus monkey (Macaca mulatta) model of the human disease. Mem Inst Oswaldo Cruz 2002;97(07):1041-1048

62 Pulcini C, Massin S, Launay O, Verger P. Factors associated with vaccination for hepatitis $B$, pertussis, seasonal and pandemic influenza among French general practitioners: a 2010 survey. Vaccine 2013;31(37):3943-3949

63 Silvestre R, Cordeiro-Da-Silva A, Santarém N, Vergnes B, Sereno D, Ouaissi A. SIR2-deficient Leishmania infantum induces a defined IFN- $\gamma /$ IL-10 pattern that correlates with protection. J Immunol 2007;179(05):3161-3170

64 Kedzierski L, Curtis JM, Doherty PC, Handman E, Kedzierska K. Decreased IL-10 and IL-13 production and increased CD44hi T cell recruitment contribute to Leishmania major immunity induced by non-persistent parasites. Eur J Immunol 2008;38(11): 3090-3100

65 Selvapandiyan A, Dey R, Nylen S, Duncan R, Sacks D, Nakhasi HL. Intracellular replication-deficient Leishmania donovani induces long lasting protective immunity against visceral leishmaniasis. J Immunol 2009;183(03):1813-1820

66 Carrion J, Folgueira C, Soto M, Fresno M, Requena JM. Leishmania infantum HSP70-II null mutant as candidate vaccine against leishmaniasis: a preliminary evaluation. Parasit Vectors 2011; 4:150. Doi: 10.1186/1756-3305-4-150

67 Breton M, Tremblay MJ, Ouellette M, Papadopoulou B. Live nonpathogenic parasitic vector as a candidate vaccine against visceral leishmaniasis. Infect Immun 2005;73(10):6372-6382

68 Taylor VM, Muñoz DL, Cedeño DL, Vélez ID, Jones MA, Robledo SM. Leishmania tarentolae: utility as an in vitro model for screening of antileishmanial agents. Exp Parasitol 2010;126(04):471-475

69 Raymond F, Boisvert S, Roy G, et al. Genome sequencing of the lizard parasite Leishmania tarentolae reveals loss of genes associated to the intracellular stage of human pathogenic species. Nucleic Acids Res 2012;40(03):1131-1147

70 Azizi H, Hassani K, Taslimi Y, Najafabadi HS, Papadopoulou B, Rafati S. Searching for virulence factors in the non-pathogenic parasite to humans Leishmania tarentolae. Parasitology 2009;136 (07):723-735

71 Mizbani A, Taheri T, Zahedifard F, et al. Recombinant Leishmania tarentolae expressing the $\mathrm{A} 2$ virulence gene as a novel candidate vaccine against visceral leishmaniasis. Vaccine 2009;28(01): 53-62

72 Breton M, Zhao C, Ouellette M, Tremblay MJ, Papadopoulou B. A recombinant non-pathogenic Leishmania vaccine expressing human immunodeficiency virus 1 (HIV-1) Gag elicits cell-mediated immunity in mice and decreases HIV-1 replication in human tonsillar tissue following exposure to HIV-1 infection. J Gen Virol 2007;88(Pt 1):217-225

73 Salehi M, Taheri T, Mohit E, Zahedifard F, Seyed N, Taslimi Y, et al. Recombinant Leishmania tarentolae encoding the HPV type 16 E7 gene in tumor mice model. Immunotherapy 2012;4:1107-1120. Doi: $10.2217 /$ imt.12.110 